\title{
Transition From Face-to-Face to Online Instruction During the COVID-19 Pandemic: An Exploration of Iranian EFL University Lecturers' Attitudes
}

Shiva Azizpour ( $\nabla$ sh.azizpour@urmia.ac.ir)

Department of English Language, Urmia University

Original article

Keywords: Attitude, COVID-19, Online Instruction, Online Learning

Posted Date: June 28th, 2021

DOI: https://doi.org/10.21203/rs.3.rs-658850/v1

License: (c) (1) This work is licensed under a Creative Commons Attribution 4.0 International License.

Read Full License 


\section{Abstract}

The COVID-19 pandemic is a huge challenge that has influenced university lecturers and students globally and led to a rapid transition from face-to-face to online instruction. The current qualitative study explored the Iranian EFL university lecturers' attitudes toward online instruction during the COVID-19 outbreak. Based on a researcher-developed protocol, semi-structured interviews were conducted with 13 university lecturers from Karaj and Science and Research Branches of Islamic Azad University, in Karaj and Tehran, Iran, whose teaching experiences ranged from 7 to 27 years, with the purpose of identifying their attitudes, experiences, and challenges regarding online instruction during the COVID-19 Pandemic. The interviews drew upon emergent methodology to categorize the interviewees' value-laden comments into four major attitudinal themes, namely, change in pedagogy, supporting students, ethics in online instruction, and the future of online instruction. The findings revealed that Iranian EFL university lecturers require professional training on the latest technology updates for online instruction and should make their online classes interactive to help their students stay focused on the course and minimize the sense of isolation. Besides, the adequacy of technological infrastructure and free internet access could facilitate online instruction during the COVID-19 outbreak. Therefore, universities and educational organizations are expected to promote the infrastructure and provide a variety of internet access alternatives. Moreover, after this global pandemic, when normal classes resume, university lecturers and students should be encouraged to continue using online tools to develop teaching and learning.

\section{Introduction}

Coronavirus disease, often referred to as COVID-19, is a threatening and dangerous disease that was reported by World Health Organization on January 30, 2020. The Coronavirus pandemic started in China in November 2019 (Liu, Zhang, Chen, Xiang, Song, Shu, \& Liu, 2020) and spread rapidly all over the world, causing severe and unanticipated health, psychological, social, spiritual, and economic problems for many individuals (Huang, Wang, Li, Ren, Zhao, Hu, \& Cao, 2020). Viner, Russell, Croker, Packer, Ward, Stansfield, and Booy (2020) reported that the COVID-19 pandemic seriously affected university students in many countries throughout the world. Due to this global pandemic, universities and other educational institutions in many countries were forced to cease face-to-face learning approach and rapidly switch to online instruction approach in the spring of 2020 to ensure that learning remains uninterrupted during the Coronavirus pandemic. In the context of this global pandemic, a new instructional setting emerged that required reflection and study (Doyumğaç, Tanhan, \& Kiymaz, 2021).

The notion of online instruction is over 170 years old and has its origins in a correspondence course where students and instructors communicated through mail in the United Kingdom. E-learning, online learning, and virtual learning concepts have been employed since 1999. Throughout history, the philosophy of online learning has been well-organized and initial e-learning techniques began in the 19th century (Saed \& Arbabi, 2018). The initial online learning programs were based on information exchange rather than sufficient student engagement. E-learning became increasingly interactive in the 1970s. The Open University in the United Kingdom conducted an online learning system to maximize its capabilities. 
The internet provided a variety of interactive courses as well as communication between instructors and students via email (Saed \& Arbabi, 2018). With the advent of the internet, computers, e-learning technologies, and new methodologies in the late 20th century, e-learning has grown in a variety of ways. People in the 1980s had computers in their homes and utilized them to learn certain skills and courses. The online learning environment was created since people had more access to online information. Saed and Arbabi (2018) pointed out that online courses became more popular in numerous institutions and universities by the early 1990s. Using the internet had a significant impact on education. Distance learning has become more affordable due to technological advancements. Technological progress opened a modern horizon in the field on e-learning. The number of people participating in online learning courses at educational institutes has risen all over the world.

In the past 20 years, considerable research regarding online instruction in higher education demonstrated that students who were enrolled in full online learning programs were faced with a system shock and were not familiar with such experience (Fawaz, Samaha, 2020). In recent years, online learning has emerged as one of the most effective educational approaches and the role of technology in foreign language development is a crucial topic (Loewen, Isbell, \& Sporn, 2020; Reinders \& Stockwell, 2017; Rosell-Aguilar, 2018). Thus, today's online learning offers valuable educational materials employing a variety of media, as well as the capacity to enable both synchronous and asynchronous communication between teachers and students (Aboagye, 2020; Means, Toyama, Murphy, Bakia, \& Jones, 2009).

Online instruction is a new type of educational instructor-delivered instruction over the internet that involves asynchronous and synchronous communication (Feldman \& Zucker, 2002). Moreover, as a result of using a web-based environment, instructors and students become more familiar with technology and students become more autonomous and reflective in an online learning environment. By ensuring that online instruction is carried out by qualified instructors who are interested in teaching in an online environment, the link between online instruction and the values of traditional instruction might be established (Khoshsima, Saed, Arbabi, 2018).

Feldman and Zucker (2002) introduced two approaches to online instruction in terms of synchronous and asynchronous instruction. Synchronous instruction is characterized as a real-time teaching and collaborating through the internet that involves audio or video conferencing, whiteboard, screen, or slide sharing, and a live chatting. On the contrary, asynchronous instruction employs the internet's time-delayed capabilities and involves podcasts, file attachments, e-mail, discussion board, blogs, and weblogs (Feldman \& Zucker, 2002).

The majority of Iranian universities employ a face-to-face pedagogy. However, due to the global pandemic, which necessitated social isolation and the temporary closure of universities, an emergency online instruction system was established. In the Iranian EFL context, there is a gap concerning the attitudes of university lecturers toward online instruction in the COVID-19 pandemic. Moreover, through investigating Iranian EFL university lecturers' attitudes toward online instruction, curriculum developers can help course designers, university students, and professors to incorporate the internet into their 
pedagogical processes. Further, professors and students can gain insights into the nature of online instruction and benefit more from online teaching and learning practices. Thus, the current study aimed at discovering the attitudes the Iranian EFL university lecturers' hold toward online instruction during the COVID-19 pandemic. Besides, it intends to explore the challenges these university lecturers face regarding online instruction during the global pandemic. University lecturers are the key agents in the utilization of any reform-based innovations and, due to the importance of the role of university lecturers, their attitudes are significant. In addition, the relationship between university lecturers and students and the challenges they face in online instruction affect the outcome of instruction. Therefore, an essential factor that affects the use of web-based technology in university students' online classes is the attitudes of university lecturers toward online instruction and it becomes of paramount importance to delve into the perceptions of university lecturers regarding online instruction in the global pandemic. Moreover, in the literature, university lecturers' attitudes toward online instruction have not been addressed, and to the best of the researcher's knowledge, there have not been any studies in the literature on the attitudes university lecturers hold toward online instruction in the world in general and in Iranian EFL context in particular. Thus, this research topic has remained under-researched, and this prompted the researcher to undertake this study.

\section{Review Of The Literature}

Coronavirus disease 2019 (COVID-19) has affected many countries all over the world. Most universities, colleges, schools, and institutions throughout the world offer online instruction to avoid disruptions in education during this global pandemic. The efficacy of online instruction is still debatable. Online instruction has long had a high dropout rate and low academic achievement. However, in order to ensure uninterrupted learning throughout the global pandemic, universities had no choice but to convert their curriculum to online delivery. As a result, officials and stakeholders rushed to adapt to the unanticipated shift (Liguori \& Winkler, 2020; Tanhan, 2020). Moreover, both synchronous and asynchronous approaches to online instruction were expected to become successful (Jiao \& Hu; 2021).

There are a variety of terms to describe the education that is conducted employing digital tools such as online, internet-based, distance, flexible, organized program, organized course, mixed, blended, and open instruction. Besides, online instruction is the most frequently employed title to describe technology-based education. However, the terms online learning, distance education, and e-learning have also been used (Doyumgaç, Tanhan, \& Kiymaz, 2021; Lee, 2010; Saykılı, 2018; Tanhan, 2020).

Online instruction is a type of education that allows the teacher and physically-distant students to collaborate on structured and planned learning experiences using a variety of multi-way mediated media channels. Online instruction enables the teacher, students, and materials to interact without needing all participants to be online at the same time. Courses are often taught online in an online learning environment, and the teacher and students must have access to the internet (Saykılı, 2018). The extensive use of online instruction brings students to a variety of places for online learning. An entirely virtual or online teaching, web-facilitated instruction, and blended or hybrid instruction are some of the changes 
that might be made with online language instruction (Atmojo \& Nugroho, 2020; Plaisance, 2018). Further, the educational method assisted by social learning and information technology that allows communication between teachers and students through everyday interaction is known as online instruction. The majority of online teachers and students have insufficient experience in a variety of areas and the most common subject is online teaching/learning (Doyumgaç et al, 2021). E-learning is the foundation of online instruction and a prominent terminology that is used to describe digital learning technology. Moreover, e-learning, online teaching, and distance instruction are the widely used concepts and foundation of online education (Lee, 2010).

The following are the main features of online instruction: (a) Online instruction offers a variety of educational opportunities. (b) The computer-assisted online instruction can be synchronous or asynchronous. (c) Online instruction can enhance or replace traditional classroom instruction. (d) Online instruction might be employed in a variety of situations, including formal and informal settings, academic and non-academic contexts. (e) Different kinds of technologies can be used for online instruction in terms of podcasts, smart whiteboards, internet calls, and mobile phones (Saed \& Arbabi, 2018).

Over the past 20 years, researchers and educators from around the world have highlighted the significance of different sets of skills and competencies required by online instructors and pointed out that mobility and flexibility are the essential characteristics of an EFL instructor in an online environment. Thus, integrating the professions of a material developer, methodologist, manager, and linguist assists EFL teachers in enhancing their skills and ensuring competitiveness, efficiency, and flexibility of online instruction. (Kolesova, Moskovkin, \& Popova, 2021; Zankov, 2019).

Furthermore, technology has an eye-catching role in today's society in the sense that most universities, schools, and institutions benefit from the use of technology to make learning process more pleasurable and effective, facilitate students' learning, and create a better learning environment. According to Kia Heirati and Ahmadi Alashti (2015), the following are the most considerable benefits of online language instruction: (a) The Internet allows individuals to practice language without leaving their houses. (b) Students can learn a language whenever and wherever they choose. (c) The internet allows students to receive immediate feedback and develop their learning process. (d) Students might encounter the language in a repetitive manner until they have mastered it. (e) The internet is a multi-modal instrument for learning that can enhance language acquisition. (f) The internet gives language learners a lot of options and diversity in terms of what they may learn and with whom they may study it. Therefore, learning may be adjusted to each student's specific needs. Further, Prichard (2013) highlighted the significance of social networking sites in English language learning and noted that these networking sites can be used to enhance students' communication skills, develop their language acquisition, and assess their work. Jones (2013) asserted that "the goal of most TESOL research studies on using technology is the measurement or description of learning outcomes under different kinds of mostly controlled conditions" (p. 844). Moreover, understanding the processes provided by social networking sites may lead to the enhancement of resources that exist outside the class and course structure (Holland, 2019; Jones, 2013). 
Semerci and Aydin (2018) pointed out that an attitude is a factor that influences an individual's conduct based on his ideas and emotions. Besides, it is considered as the degree of positive or negative impact associated with a certain belief or concept. Instructors' positive attitudes and beliefs toward using technology and online teaching significantly influenced their instruction (Huang \& Liaw, 2005; Keeton, 2004). In the same vein, Kayzouri, Mohebiamin, Saberi, and Bagheri-Nia (2020) put under the spotlight the importance of instructors' attitudes toward online instruction and demonstrated that instructors' attitudes inevitably have a significant role in determining the success or failure of their instruction in an online environment.

University lecturers' attitudes play a central role in using technologies for online courses (Bozorgian, 2018). Instructors' views about technology use can be viewed as a hindering or facilitating factor, allowing or preventing them from using technology in their classrooms. Moreover, internet technologies and computers are the most effective technical aids for language teaching. Thus, employing the internet in the classroom can assist students in learning a foreign language more efficiently (Kia Heirati \& Ahmadi Alashti, 2015; Kim, 2002). Further, university lecturers' attitudes toward online instruction may have a great impact on the success or failure of their teaching. Therefore, instructors' pessimistic perceptions of technology might influence their students' attitudes toward the internet. Besides, the new curriculum may not be successful if instructors have unfavorable views toward changing established teaching methods (Kia Heirati \& Ahmadi Alashti, 2015).

Online instruction has been examined by different researchers and scholars from a diverse range of aspects. For instance, in a quantitative study, Gasaymeh (2009) investigated Jordanian university professors' perceptions toward internet-based online education through employing online questionnaires and short phone calls. The findings of the study demonstrated that the participants had positive perceptions toward internet-based e-learning.

In another study, Atai and Dashtestani (2013) employed a questionnaire, observations, and interviews to examine 723 students, 67 EAP lecturers, and 105 CE lecturers' perceptions toward the internet in EAP courses in Iranian universities. The findings of the study revealed that the majority of the participants held positive perceptions toward the internet. On the contrary, the findings demonstrated that the lecturers did not use internet-based activities in their classes.

On the other hand, Bozorgian (2018) investigated EFL instructors perceptions toward implementing mobile-assisted language learning. To this end, he collected the data through observation, questionnaire, and structured interviews with 10 instructors from Mazandaran, Iran. Afterwards, one-sample t-test was run to analyze the data. The questionnaire's data indicated that the participants held positive perceptions toward implementing mobile-assisted language learning. However, the findings of the observations revealed that most of the participants preferred traditional instruction. Meanwhile, the structured interviews' data demonstrated that the participants faced certain challenges regarding implementing MALL instruction in their EFL classes, such as their limited knowledge of e-learning, inadequate resources, and insufficient interaction in online teaching. 
In a recent case study, Mahmood (2020) investigated various instructional strategies for implementation of online instruction in higher education and demonstrated that some strategies played a critical role in developing students' learning in terms of sending the materials to students before the class, and speaking slowly. Further, the study indicated that recording online courses, getting students' feedback, and providing them with various instruction and assessment policies enhanced distance education.

Furthermore, in a very recent study, Daniels, Goegan, and Parker (2021) employed a single survey to collect retrospective data from 98 Canadian undergraduate students about their engagement, motivation, and perceptions of success and cheating before the global pandemic and then in distance learning. The participants of the study were selected based on convenience sampling. Further, the researchers used regression analyses to investigate the relationship among the variables. The results revealed that the participants' engagement, achievement purposes, and perceptions of success significantly minimized, while their perceptions of cheating maximized. Besides, mastery-approach purposes were significantly associated with more engagement and higher perceptions of success and achievement purposes were not related to cheating.

In another very recent study, Chen, Jiao and Hu (2021) examined $60 \mathrm{EFL}$ college students' learning outcome, engagement, and their attitudes toward online courses featured with several tasks and quizzes as formative assessment. The researchers collected the data during the first five weeks of a course that was switched from mixed learning to totally online due to the closure of the college. The results of the study demonstrated that students actively engaged in online learning tasks and obtained high marks in all examinations, quizzes, and tasks.

Ultimately, Meishar-Tal and Levenberg (2021) investigated 239 academic instructors' feelings of opportunity, threat, failure, and success toward online teaching during the Coronavirus pandemic and the impact of their feelings on their desire to teach in an online environment through employing a questionnaire. The results revealed that accomplishment and opportunity were the strongest feelings perceived by the instructors. Moreover, feelings associated with failure and opportunity were found to be the predictors of the participants' desire to teach in an online environment. Further, during the first semester of the pandemic, the dramatic crisis unexpectedly inspired more positive than negative feelings among the instructors.

The present study subscribes to Garrison, Anderson, and Archer's 'community of inquiry model' (2000) as its theoretical framework. This model confers the greatest importance to three distinct 'presences': cognitive, social, and teaching. Besides, it supports the design of online and blended courses as active learning environments or communities dependent on professors and students sharing ideas and information. It is worth noting that 'presence' is a social phenomenon and expresses itself via interactions among professors and their students. Further, the community of inquiry model (COI) is one of the most popular models of online instruction and learning for online courses that are designed to be highly interactive among students and their instructor using blogs, discussion board, chat box, and audio or video conferencing. 
The review of the studies conducted during the Coronavirus pandemic demonstrated that the studies on online instruction were mostly conducted with quantitative methods through questionnaires. However, since the current study employed a methodology that was not used in the previous studies, it could fill the gap in the literature. Further, the present study makes a unique contribution to this field, as it offers a detailed account of the Iranian EFL university lecturers' attitudes toward online instruction during the COVID-19 Pandemic. To the best of the researcher's knowledge, there have not been any studies in the literature on the attitudes EFL university lecturers hold toward online instruction during the COVID-19 pandemic in Iran. Thus, the following research question was formulated to address the objective of the current study: What attitudes do Iranian EFL university lecturers hold toward online instruction during the COVID-19 pandemic?

\section{Method}

\subsection{Participants}

The participants of the current study were 13 university lecturers and were selected from Karaj and Science and Research Branches of Islamic Azad University, in Karaj and Tehran, Iran, based on convenience sampling. Table 1 provides information on the participants of this study. The university lecturers comprised nine females and four males. Their ages ranged from 28 to 49 , with 7-27 years of teaching experience. The participants had Ph.D., or they were Ph.D. candidates in TEFL, Translation Studies, or English language and literature. It must be noted that the names of the university lecturers are not disclosed in the study to maintain anonymity.

Table 1. Participants' Academic Degree, Field of Study, and Teaching Experience

\section{Participants}

Years of Teaching Experience

1. University Lecturer (UL1) 27

2. University Lecturer (UL2) 19

3. University Lecturer (UL3) 15

4. University Lecturer (UL4) 7

5. University Lecturer (UL5) 20

6. University Lecturer (UL6) Literature 18

7. University Lecturer (UL7) 13

\section{Degree}

Ph.D.

Ph.D.

Ph.D.

Ph.D.

Ph.D.

Ph.D.

Ph.D. Candidate

TEFL
Field of Study

TEFL

TEFL

TEFL

TEFL

Translation Studies English Language and 


\begin{tabular}{|c|c|c|}
\hline $\begin{array}{l}\text { 8. University Lecturer (UL8) } \\
8\end{array}$ & Ph.D. Candidate & TEFL \\
\hline $\begin{array}{c}\text { 9. University Lecturer (UL9) } \\
7\end{array}$ & Ph.D. Candidate & TEFL \\
\hline $\begin{array}{c}\text { 10. University Lecturer (UL10) } \\
15\end{array}$ & Ph.D. Candidate & Translation Studies \\
\hline $\begin{array}{l}\text { 11. University Lecturer (UL11) } \\
13\end{array}$ & Ph.D. Candidate & Translation Studies \\
\hline 12. University Lecturer (UL12) & Ph.D. Candidate & English Language and \\
\hline Literature & & \\
\hline 13. University Lecturer (UL13) & Ph.D. Candidate & English Language and \\
\hline Literature & & \\
\hline
\end{tabular}

\subsection{Instruments}

In order to answer the research question of the present study, semi-structured interviews based on the interview protocol developed by the researcher were conducted. The initial items for the interview protocol were developed based on a thorough review of the related literature and the researcher's experience and knowledge of supervision in Iranian language schools. Besides, the researcher set up one group interview session with three university professors in order to initially try out the interview questions and revise them in light of the given suggestions and comments. Moreover, in order to validate the interview questions, two associate professors and an assistant professor in Applied Linguistics commented on them. The interviews drew upon emergent methodology to categorize the interviewees' value-laden comments into four major attitudinal themes, namely, change in pedagogy with four subthemes of online teaching software, synchronous versus asynchronous teaching, benefits of online instruction, and university lecturers' challenges regarding online instruction, supporting students with two subthemes of establishing rapport and positive relationship with students and student engagement, ethics in online instruction with a subtheme of assessment in an online environment, and the future of online instruction with two subthemes of university lecturers' suggestions or recommendations regarding online instruction and changes in learning approaches after the COVID-19 pandemic. (See the Appendix for the complete interview protocol).

\subsection{Procedure and Data Analysis}

As the present study was attitudinal in its scope and nature, it employed the principles of qualitative research (Denzin \& Lincoln, 2000) to collect data, investigate the participants' attitudes, and find out the answer to the research question of the study. Most of the qualitative studies which intend to explore the theory inherent in the data inductively and deductively follow an emergent methodology. Therefore, the current study intended to focus on the insightful attitudes regarding online instruction during the COVID19 pandemic that appeared from the data through employing the procedures followed by Grant-Davie (1992), Miles and Huberman (1994), and Coffey and Atkinson (1996). It is worth mentioning that the researcher supplemented this approach by an in-depth content analysis (Dawson, 2002), a method in 
which a researcher analytically examines interview transcripts and assigns codes to the emergent concepts. Thus, in line with Harwood, Austin, and Macaulay (2009), the researcher conducted interviews to explore the Iranian EFL university lecturers' attitudes toward online instruction during the COVID-19 pandemic.

Furthermore, in order to achieve the desired goals of the study, the researcher developed a set of interview questions for university lecturers. It should be noted that the researcher followed semi-structured interview protocol and asked more open-ended questions, allowing for a discussion with the interviewees rather than a straightforward question and answer format. The interviews with the university lecturers were conducted either face to face or through Skype, lasting between 35 and 55 min, audio-recorded, and transcribed verbatim by the researcher. The transcripts were sent to the participants for verification and possible modification through email.

Afterwards, the researcher manually coded and categorized the transcribed data to identify "value-laden instances" (Silverman, 2000) which indicated the university lecturers' attitudes toward online instruction during the COVID-19 pandemic. To help readers track each participant's contribution, the researcher assigned a code name to each participant. For example, UL1 stands for University Lecturer Number 1 (see Table 1). Further, significant to note here is the wording of the interview extracts. As is evident in the results, some of the interviewees' comments on a single question mentioned the same opinion, and the voices were mostly similar. Therefore, when reporting the number and identities of the interviewees who raised a similar issue, the researcher provided a number of sample extracts taken from the participants as support for an issue. Thus, the researcher analyzed and reported the transcriptions based on the research question and research purpose in order to explore the EFL university lecturers' attitudes toward online instruction during the global pandemic.

\section{Results}

The research question of the current study dealt with the attitudes the Iranian EFL university lecturers held toward online instruction during the COVID-19 pandemic. In this section, the researcher reports and describes the participants' attitudes through employing supporting extracts from the interviews. The university lecturers participating in this study were asked eleven questions.

\subsection{Change in Pedagogy}

The first major attitudinal theme of the interviews was change in pedagogy, with four subthemes of online teaching software, synchronous versus asynchronous teaching, benefits of online instruction, and university lecturers' challenges regarding online instruction.

All of the university lecturers pointed out that, during the COVID 19 pandemic, instruction is conducted online, using different devices connected to the internet. Besides, the instructors noted that they interact with their students through email or Telegram. Moreover, the interviewees asserted that instructors and 
students cannot see each other unless recorded videos or images are made available. The following comments from UL1, UL2, and UL6 elucidate this:

"During this global pandemic, I teach course materials through the explicit use of technology and computer networking systems, without any physical or face-to-face activities or meetings to enable my students to participate in their learning activities beyond the university classroom."

"My colleagues and I are required to teach our students through distance learning which involves network delivered computer based instruction and online tools and methods. We also need to interact with our students via email or Telegram rather than face-to-face."

"The COVID-19 outbreak caused our university to implement online instruction for the sake of controlling the spread of the global pandemic. Thus, since we were unable to meet in a face-to-face setting during the current COVID-19 pandemic, online teaching in the EFL context occurred entirely online and we had to adjust to online instruction in response to this global pandemic."

Furthermore, out of 13 university lecturers, four pointed out that university students are expected to be more autonomous in an online learning environment. The comment from UL13 demonstrates this point:

"Pedagogy used for face-to-face learning is not feasible for online instruction. Online instruction is mostly based on materials such as readings or exercises and offers the opportunity to integrate more media. Connecting university students and professors through digital platforms, laptops, and cell phones is the latest transition in online education. In addition, in an online learning environment, our students are required to be more autonomous."

\subsubsection{Online Teaching Software}

All of the interviewees asserted that during this global pandemic, they teach courses through web-based technologies, from the internet that enables students to participate in learning activities beyond the classroom. In this regard, all of the university lecturers indicated that they employ Daan platform to hold their online classes. Moreover, nine interviewees highlighted the importance of using social media like Telegram channels as a tool to supplement online courses. This is evident in the following excerpts from UL2 and UL13:

"My colleagues and I are required to hold our online classes through Daan platform of Islamic Azad University. On the other hand, Telegram channels provide a considerably effective mobile platform during the current global pandemic and offer more functionalities and fewer potential drawbacks than other applications."

"Other than using Daan platform, I often provide my students with additional resources and coaching through private Telegram channels that are created for each course at the beginning of the semester."

\subsubsection{Synchronous versus Asynchronous Teaching}


All university lecturers spoke about the advantages and disadvantages of synchronous and asynchronous teaching environments and pointed out that synchronous instruction is mostly voice dependent and limits flexibility for students. Because of the need for everyone to be online at the same time, the instructor and students are required to work through the course at a similar pace in the synchronous environment. On the contrary, they noted that although asynchronous instruction has higher level of temporal flexibility, it lacks the real-time interaction between the instructors and their students. The following comments from UL8 and UL12 elucidate this:

"Asynchronous online instruction cannot be that much beneficial. In an asynchronous environment, course materials may be misunderstood, and instructor to student interactivity is limited to an email when our students have a question or problem. In contrast, in a synchronous environment, we are connected by audio conferencing and the students can ask their questions in real time like a face-to-face environment. In addition, there are a number of tools that can support synchronous teaching such as: instant messaging or whiteboard sharing."

"I have experienced them both. In asynchronous online teaching, the teaching materials were sent online, and my students worked through the materials in their own time and communicated with me through my email. However, synchronous teaching was more useful and took place through voice conferencing and live chat."

Furthermore, all of the university lecturers highlighted the significance of collaboration in synchronous and asynchronous online learning environments. The comment from UL4 demonstrates this point:

"I believe that collaboration between the instructor and students is considered as a crucial factor in both synchronous and asynchronous teaching environment and it creates a sense of connection and shared purpose between them."

\subsubsection{Benefits of Online Instruction}

As the sample extracts from UL5 and UL7 reveal, nine university lecturers (UL2, UL3, UL4, UL5, UL7, UL8, UL11, UL12, and UL13) reported that promoting student autonomy, reducing student anxiety, recording online sessions, reviewing the lessons multiple times, offering more effective ways to deliver course materials to students, holding classes in more comfortable physical conditions, promoting virtual communication and collaboration, and developing technical skills are the most important benefits of online instruction.

“Online environment assists university lecturers in minimizing their students' anxiety and also students may become more autonomous in an online environment. Another important benefit of online instruction is that students can record their online sessions and review them several times. In addition, students can improve their virtual communication skills."

"As a part of their coursework, students need to use online learning materials, get familiar with new software and tools, and troubleshoot common issues. Therefore, they can develop their technical skills in 
an online learning environment."

Furthermore, UL13, Ph.D. in TEFL, with 10 years of teaching experience, noted that university students do not sometimes feel comfortable asking their professors to repeat a point they made in their last lecture or dive into deeper details on a particular topic. Thus, when learning online, they can revisit the last material, perform additional research, and organize their notes. Moreover, UL1 maintained that online instruction involves a variety of efficient tools in terms of podcasts, videos, Power Point and PDF files that can be used by instructors as a part of their lesson plans. The statement from UL3 demonstrates this:

"University instructors can become more efficient educators by extending the lesson plan beyond traditional textbooks to include different online resources."

On the other hand, the interviewees put under the spotlight the significance of flexibility of place in online teaching environment. Besides, they asserted that students who live in different cities or lack time to attend their courses can considerably benefit from online instruction. This is evident in the following excerpts from UL2, UL4, and UL9:

"For those students who live in another city or need to juggle working and going back to university, the flexibility of an online program provides them with the opportunity to learn while they are at work. Therefore, this flexibility allows them to balance their education, work, and life."

"In face-to-face classes, there was a preparation process that involved dressing and ironing. However, in online classes, it is enough to be next to my laptop in a comfortable place in our home five minutes before the class. As a result, it is so comfortable and contributes to focus on the course."

"Another considerable benefit of online class is that it allows the instructor and students to attend the class from home or any other location of their choice. Thus, online teaching environment offers them the accessibility of place in education."

\subsubsection{University Lecturers' Challenges Regarding Online Instruction}

Seven interviewees (UL1, UL3, UL5, UL6, UL7, UL8, and UL10) asserted that facing technology and internet connectivity issues, harming instructors and students' eyes, focusing on the screen for a long period of time, developing physical problems, having a sense of isolation, and having minimal interactions between the instructor and students are the most important challenges university lecturers and students face regarding online instruction. This is evident in the following statements from UL4, UL7, UL11, and UL12:

"This pandemic has raised several challenges for the higher education community. Poor internet connectivity is one of the important challenges of online classes. Without a consistent and reliable internet connection for university lecturers or students, there will be a lack of continuity in learning for students." 
"Laptop or cell phone screens harm instructors and students' eyes if they continue to look at the screen for a long time."

"There is no face-to-face interaction between the professor and students in an online learning environment and this issue results in a sense of isolation for the students."

"Instructors and students may develop physical problems due to staying hunched in front of a screen. I am really concerned about the health hazards of having myself spend too many hours staring at my laptop screen. Thus, this increase in screen time is one of the most important disadvantages of online instruction."

On the other hand, UL3 and UL5 spoke about financial constraints and lack of experience, awareness, and training to use digital forms of learning, respectively:

"Online learning requires professors and students to have a basic knowledge of using digital forms of instruction and learning. However, some of our students have inadequate knowledge of how to use online tools and those from poor families do not even have the necessary tools to join online classes."

"Professors are not trained for online instruction and some of the old instructors might not even know how to teach online and prepare appropriate materials for online classes. On the other hand, adjunct professors need to spend money from their own pockets to use high-speed internet facilities to teach in their online classes."

\subsection{Supporting Students}

The next major attitudinal theme of the interviews was supporting students with two subthemes of establishing rapport and positive relationship with students and student engagement.

\subsubsection{Establishing Rapport and Positive Relationship with Students}

All of the university lecturers underscored the significance of caring, empathy, availability, and enhanced communication in establishing rapport with their students in an online environment and demonstrated that rapport is one of the crucial factors that contributes positively to their students' development. Besides, they noted that university professors and students need to trust and respect each other in order to build positive relationship in their online classes and students will feel more supported if their instructors show sincere interest in them as individuals. These points are evident in the following statements from UL1 and UL6:

"Trust is necessary for developing rapport and positive relationship with our students. On the other hand, we should be respectful and available to our students, establish empathy, and assist them in reducing their anxiety levels through interacting with them."

"During this global pandemic, some of our students are experiencing high levels of anxiety. Therefore, it is important to assist them in minimizing their anxiety. Additionally, if our students realize that we care 
about their development and success, they will be more likely to engage with us and their course materials."

UL4, Ph.D. in TEFL, with seven years of teaching experience, put under the spotlight the importance of calling students by their first names and remembering the details. In this regard, she pointed out that:

"We understand each other better when there is rapport between us. I always call my students by their first names in our online classes and remember the details regarding their learning process in order to build rapport and positive relationship with them."

\subsubsection{Student Engagement}

Six university professors (UL2, UL6, UL7, UL9, UL11, and UL12) asserted that employing praise and positive feedback, providing students with opportunities to reflect on their own learning experiences, and being open to their feedback can bring motivation and engagement in their students' learning. Moreover, they noted that building a positive relationship with students can truly motivate them to engage in the online environment and develop their performance. Further, UL11 highlighted the importance of using a variety of instructional methods and stated that:

"I always try to provide positive feedback on my students' performance in my online classes. On the other hand, my willingness to listen to my students' feedback will make them feel comfortable in sharing their reflections with me in our online class. I also make my online courses accessible, use different instructional methods, and enrich each lesson with Power Point files and textual information in the lesson, along with some videos illustrating the key points."

On the other hand, UL10, with 15 years of teaching experience, noted that an instructor's enthusiasm is one the crucial factors in increasing students' motivation. Moreover, she highlighted the importance of having a good learning environment and expressed that:

“Learning environment has an important role in students' success in an online course. A good and supportive online learning environment can help our students stay engaged. In addition, inspired professors can inspire their students as well."

\subsection{Ethics in Online Instruction}

Another major theme of the interviews explored the university lecturers' attitudes toward the role of ethics in an online learning environment, with a subtheme of assessment in an online environment.

All of the interviewees highlighted the significance of ethical issues in an online learning environment and spoke about being fair, polite, respectful, honest, and trustworthy, considering each student's face, being aware of the tone of their language, respecting students' emotions and feelings, controlling their behaviors and actions, answering students' questions, avoid being defensive, preventing discrimination against students, avoid using offensive language, checking interactions among students in the online 
class, and making students aware of their commitment to the ethics in an online learning environment. The following comments from UL9 and UL11 elucidate these points respectively:

"In my view, politeness, fairness, respect, and tolerance are extremely important in an online learning environment. Besides, I always control my behavior and avoid using insulting language. Moreover, in answering my students' questions in our online classes, as a sign of courtesy and respect for the students, I answer them as soon as possible."

"In my online classes, my students are required to respect each other, conduct interaction based on predetermined rules, and be aware of the issues associated with ethics in online courses. I always supervise the processes of collaborative learning development of my students, check the interactions among them in our online class, and never let them insult their peers. When something is annoying in the online class, I try to react calmly and without any kind of violence or aggressiveness. Additionally, in case of any violence, I report it to the head of our faculty in order to take appropriate action."

Further, all of the interviewees put under the spotlight the significance of being committed to their work and being organized in an online learning environment. Moreover, they demonstrated that students need structure for success. This is evident in the following excerpt from UL10:

"When a professor and students are organized and have clear instructions and schedules, their uncertainty is minimized. However, unfortunately, I know some instructors who are too disorganized. They are frequently late for their classes or leave their classes early, unable to find their materials for their online classes quickly, and not comfortable and up to date with their course content."

\subsubsection{Assessment in an Online Environment}

Out of 13 university lecturers, nine spoke about several strategies to minimize cheating on online final examinations and pointed out that assessment is the most challenging part of the transition from physical to online teaching environment. However, they stated that creating open-ended questions, starting the exam at a specific time, limiting how long the students will have to take the exam, using plagiarism checkers to evaluate students' term projects, research papers, and assignments, designing exam questions that provoke students' critical thinking, requiring students to focus merely on one question at a time, changing test question sequence, offering different versions of the same test, and checking possible technical problems prior to each exam are of utmost importance in reducing cheating on online examinations. These points are evident in the following statements from UL8 and UL12:

"Well, in an online environment, it is hardly possible to ensure that our students do not cheat! However, I often prohibit backtracking and require my students to focus only on one question at a time, answer it, and then go to the next one. On the other hand, I usually provide different students with different versions of the same test to minimize cheating on online exams."

"There are a number of ways through which we can minimize cheating in an online environment. For instance, changing test question sequences, checking plagiarism, using varied question types, and 
designing subjective-based question types that demand higher order thinking and deeper understanding of the content in order to assess students' mastery of course materials."

On the other hand, six participants highlighted the significance of requiring their students to sign a Pledge of Ethics Form before starting their examinations. The following statement from UL13 elucidates this:

"Since online teaching and assessment are taking place as a result of the COVID-19 pandemic, students of Islamic Azad University are required to sign an Ethics Form prior to their final examinations. In fact, the Ethics Form serves as a reminder of the significance of ethical principles."

Furthermore, UL7 and UL10 put under the spotlight the importance of carrying out formative assessment and evaluating students based on their classroom practices and pointed out that university instructors should not rely too heavily or only on exams as a means of assessing their students' learning. Concerning this, they pointed out that:

"I believe that assessment is more than just scores and learning is not about grades, but about progress. I carry out formative assessments in my online courses to ongoingly and consistently determine how well my students learn the course contents and provide critical feedback to them."

"In an online learning environment, I often evaluate my students based on their classroom performance and term projects and each student's active participation is strongly recommended for all my online classes. Moreover, my students' final score includes (a) a final exam (25 percent) and (b) active class participation and assignments (75 percent)."

\subsection{The Future of Online Instruction}

The last major attitudinal theme of the interviews was the future of online instruction, with two subthemes of university lecturers' suggestions or recommendations regarding online instruction and changes in learning approaches after the COVID-19 pandemic.

\subsubsection{University Lecturers' Suggestions or Recommendations Regarding Online Instruction}

The interviewees emphasized the importance of having adequate and up-to-date computer-based and high-speed internet-based facilities, training university instructors to teach online, and providing them with economic support during the global pandemic. Further, developing university lecturers and students' online computer literacy skills, promoting students' involvement, engaging students in synchronous rather than asynchronous activities in online courses, establishing positive attitudes, showing compassion, getting students' feedback, responding to their feedback, identifying their own weaknesses, and reflecting on how to improve their courses were among the interviewees' other suggestions or recommendations regarding successful online instruction in the Iranian EFL context. In this regard, UL2 and UL6 with almost two decades of teaching experience indicated that: 
"We should receive training on online teaching principles. Besides, I believe that policymakers should provide us with economic support during the global pandemic to avoid burnout and ensure that all university lecturers and students have access to the proper devices and connection. On the other hand, professors can use other ways, such as term projects, reflective essays, and research papers, to evaluate each student's performance in an online learning environment."

"We need online facility improvement. On the other hand, since ensuring success in an online learning environment requires active engagement of students in the learning process, university lecturers are expected to promote student involvement and peer collaboration in their online courses."

\subsubsection{Changes in Learning Approaches after the COVID-19 Pandemic}

The interviewees maintained that, after this global pandemic, when normal classes resume, face-to-face EFL university courses might be combined with and supported by online teaching sessions. Besides, university professors may use these online tools to enhance their instruction. Moreover, in the future, university lecturers might have more liberty and autonomy in deciding where to integrate technology to support their teaching practices. In this respect, UL12 gave this comment:

"These days, we have to resort to online educational tools due to the COVID-19 pandemic. However, in the future, it will become a new model of education and I believe that online instruction might become an integral component of higher education. Therefore, educators might apply those teaching initiatives that have proved to be effective during distant learning and integrate them into the regular face-to-face education system."

\section{Discussion}

The present study aimed to identify the attitudes the Iranian EFL university lecturers' hold toward online instruction during the COVID-19 pandemic. As a result of conducting this research, the researcher found that, during the global outbreak, university lecturers taught their courses through web-based technologies and instruction was conducted fully online through Daan platform, Telegram channels, or email. Besides, the interviewees pointed out that their students were required to be more autonomous in an online learning environment. This may be owing to the fact that, in an online learning environment, students might control their learning management, choose where and how to learn their course contents, and use more materials not only relying on sources that have been situated by their instructor. This is echoed in the literature by Kia Heirati and Ahmadi Alashti (2015). In this respect, they illustrated that online language instruction might provide students with innovative opportunities to promote their autonomy and develop their language skills beyond the classroom. In the same vein, Baru, Tenggara, \& Mataram (2020) demonstrated that e-learning may successfully develop students' autonomy and collaboration in learning English as a foreign language.

According to the university lecturers' perceptions, synchronous instruction was mostly voice dependent and limited flexibility for students. However, asynchronous instruction had a higher level of temporal 
flexibility and lacked real-time interaction between the instructors and students. These findings are in line with some previously conducted studies (e.g. Park \& Bonk 2007; Salbego \& Tumolo, 2015). In this regard, Park and Bonk (2007) carried out a case study to examine synchronous online instruction practice in a blended program, highlighted the issues concerned with this type of instruction, and pointed out that, during synchronous online instruction, students may promote more meaningful and interactive engagement and they might be central to the effectiveness of synchronous online teaching.

Furthermore, regarding the benefits of online instruction, the interviewees noted that it promoted virtual communication and collaboration, developed their technical skills, promoted student autonomy, reduced students' anxiety, and enabled them to record the online sessions, review the lessons several times, and hold the classes in more comfortable physical conditions. Moreover, the interviewees underscored the importance of flexibility of place in an online teaching environment. These are illustrated in the literature by some scholars (Bailey \& Lee, 2020; Fageeh \& Mekheimer, 2013; Kia Heirati \& Ahmadi Alashti, 2015; Underdown \& Martin, 2016; Xia, Fielder, \& Siragusa, 2013). For instance, Xia et al. (2013) demonstrated that a variety of advantages are available in an online teaching or learning environment to EFL professors and students, such as being location-independent, not having to drive long distances to university, having more time to think and respond, and enhanced learning flexibility. Besides, online EFL teaching and learning might develop student-centered instruction and promote students' motivation and engagement (Chapelle, 2005; Gao \& Zhang, 2020).

On the other hand, the present study revealed that harming university lecturers and students' eyes, developing physical problems, facing technology and internet connectivity issues, having minimal interactions between the instructor and students, financial constraints, and lack of experience and training to use digital forms of learning are the most important sources of challenges university lecturers and students face regarding online education. One plausible justification for this finding is that as the duration of daily internet use increases, eye problems such as eye fatigue, dry eye, and tearing in the eyes also significantly increase. Therefore, eye problems could appear due to the extensive use of electronic devices such as computers and mobile phones during online courses. In addition, instead of walking from class to class, university lecturers and students often end up sitting in one spot for every class. Thus, the continuous sitting that online instruction often requires might also have negative effects on lecturers and students' bodies.

These findings are in line with some previously conducted studies (e.g. Halim \& Hashim, 2019; Pazilah, Hashim, \& Yunus, 2019). In this regard, Halim \& Hashim (2019) pointed out that instructors and students might experience certain challenges regarding online education and may face technical issues such as audio problems and poor internet connection. In the same vein, Pazilah et al. (2019) noted that the potential barrier to authentic communication opportunities is one of the important challenges regarding EFL learning in an online environment.

The findings of the study also revealed that respect, trust, empathy, caring, enhanced communication, and availability were essential in supporting students and establishing rapport and positive relationship 
with them. Remembering the details and calling the students by their first names were also significant in establishing a good relationship with them. Moreover, the university lecturers' statements indicated that being enthusiastic, building a positive relationship with students, employing praise and positive feedback, providing students with opportunities to reflect on their own learning experiences, and being open to their feedback brought motivation and engagement in their students' learning and motivated them to develop their performance and engage in the online learning environment. In the same vein, Durrington, Berryhill, \& Swafford (2006) asserted that university professors might support their students and establish positive relationship with them through employing strategies available to maximize their students' levels of interactivity, foster their motivation, and build rapport with them in online classes. In the same line, Kaufmann \& Vallade (2020) highlighted the significance of an instructor's role in establishing and maintaining rapport in an online learning environment and illustrated that rapport and connections with the instructor play a crucial role in minimizing students' perceptions of loneliness in an online learning environment.

Furthermore, the university lecturers' comments demonstrated that being organized, fair, polite, respectful, honest, and trustworthy, considering each student's face, being aware of the tone of their language, respecting students' emotions and feelings, controlling their behaviors and actions, answering students' questions, preventing discrimination against students, checking interactions among students in the online class, making students aware of their commitment to the ethics in an online learning environment, and asking them to sign a Pledge of Ethics Form before their examinations were among the crucial ethical issues in an online teaching/learning environment. These findings are in line with some previously conducted studies (e.g. Reamer, 2013; Slade \& Prinsloo, 2013; Toprak, Ozkanal, Aydin, \& Kaya; 2010). In this regard, Reamer (2013) investigated complex ethical issues associated with the proliferation of online instruction and underscored the significance of academic honesty in an online learning environment. In the same vein, Toprak et al. (2010) underscored the importance of showing respect and tolerance among students and instructors, necessitating regulations that balance varied participant expectations, and considering how students view ethics when studying online.

Further, creating open-ended questions, starting the exam at a specific time, limiting how long the students will have to take the exam, using plagiarism checkers to evaluate students' term projects, research papers, and assignments, designing exam questions that provoke students' critical thinking, requiring students to focus merely on one question at a time, changing test question sequence, offering different versions of the same test, carrying out formative assessment, evaluating students based on their classroom practices, and checking possible technical problems prior to each exam were among the critical strategies to reduce cheating on online exams. In the same vein, Varble (2014) put under the spotlight the significance of presenting one question at a time, allowing only one attempt to take test, randomizing questions and answer choices for each student, using less summative assessment and more formative assessment, and minimizing the average time to answer each question in minimizing cheating opportunities on online examinations. 
The interviewees' statements illustrated that training university instructors to teach online, providing them with economic support during the global pandemic, developing university lecturers and students' online computer literacy skills, having adequate and high- speed internet-based facilities, promoting students' involvement, establishing positive attitudes, showing compassion, getting students' feedback, responding to their feedback, and engaging students in synchronous rather than asynchronous activities in online courses, were among their suggestions and recommendations regarding successful online instruction in the Iranian EFL context. These findings are echoed in the literature by Kia Heirati and Ahmadi Alashti (2015). In this regard, they demonstrated that language instructors lack the knowledge of technology to integrate technology into their language courses. Thus, stakeholders and educators are required to provide EFL instructors with certain professional technology training opportunities to develop their technology proficiency and online literacy skills and assist them in employing the internet and computer technology to enhance their future language teaching practices.

Ultimately, the university lecturers' attitudes toward changes in teaching/learning approaches after the COVID-19 crisis demonstrated that, after this global outbreak, when normal classes resume, face-to-face EFL university courses may be supported by online teaching sessions, university professors may use these online tools to enhance their instruction, and they might have more liberty and autonomy in deciding where to integrate technology to support their instruction. In the same vein, Gao and Zhang (2020) and Moorhouse (2020) underscored the significance of inevitable role of technology in EFL learning and asserted that technology must be integrated into language learning programs.

\section{Conclusion}

The current study investigated Iranian EFL university lecturers' attitudes toward online instruction during the COVID-19 pandemic. In conclusion, this study demonstrated that Iranian EFL university lecturers have carried out online instruction synchronously via Daan platform during the Coronavirus pandemic. They have also employed additional resources, email, and Telegram channels to carry out online instruction. Further, this study gave contributions to the literature on online language instruction from Iranian EFL university lecturers' perspectives and found that Iranian EFL university lecturers require professional training on the latest technology updates for online instruction and should make their online classes interactive to help their students stay focused on the course and minimize the sense of isolation. Besides, the adequacy of technological infrastructure and free internet access could facilitate online instruction during the COVID-19 outbreak. Therefore, universities and educational organizations are expected to promote the infrastructure and provide a variety of internet access alternatives. Moreover, after this global pandemic, when normal classes resume, university lecturers and students should be encouraged to continue using online tools to develop teaching and learning.

Furthermore, the results of the current study provide some pedagogical implications that could be of benefit for EFL university professors, educators, and students. Iranian stakeholders and educators can consult these results as a means of identifying strengths, weaknesses, opportunities and threats (SWOT) analysis (Hill \& Westbrook, 1997) of online instruction in Iranian universities. SWOT analysis is a 
framework for investigating and analyzing the internal and external factors that can have an impact on the viability of a project, product, place, or person (Hill \& Westbrook, ibid). The SWOT analysis of online instruction could help Iranian stakeholders and educators develop a full awareness of all the factors involved in online instruction and improve Iranian EFL university lecturers' online teaching practices. In addition, the results of this study can assist stakeholders in exploring EFL university lecturers' strengths and weaknesses, recognizing the challenges they encounter, and offering more effective support to them. Thus, educators can draw upon the findings to provide some professional training opportunities for university lecturers on the latest technology updates to improve the quality of online instruction. Further, the findings of the study can familiarize stakeholders with the expectations Iranian EFL university lecturers harbor for online instruction and address those concerns in their future practices.

This study faced some limitations which need to be taken into account in interpreting the findings. The first limitation of this study concerns the number of the university lecturers. Thus, future studies can include more participants to yield more generalizable results. Moreover, the participants of the present study were selected from universities in Karaj and Tehran, Iran. Therefore, it made it a little difficult to provide a clear picture of all Iranian EFL university lecturers' attitudes toward online instruction during the COVID-19 pandemic. Therefore, further research can replicate this study with university lecturers from different cities of Iran or even other countries. On the other hand, the participants of the current study were selected based on convenience sampling. Thus, the study can be duplicated with other procedures to make the results more generalizable. Further, this study calls for further investigation to explore university lecturers' attitudes toward online instruction considering the differences in their gender, age, academic degree, and teaching experience.

\section{Abbreviations}

CE: Civil Engineering

COI: Community of Inquiry

COVID-19: Coronavirus Disease 2019

EAP: English for Academic Purposes

EFL: English as a Foreign Language

E-learning: Electronic Learning

MALL: Mobile Assisted Language Learning

PDF: Portable Document Format

Ph.D.: Doctor of Philosophy

SWOT: Strengths, Weaknesses, Opportunities, and Threats 
TEFL: Teaching English as a Foreign Language

TESOL: Teaching English to Speakers of Other Languages

UL: University Lecturer

\section{Declarations}

\section{Availability of data and materials}

Please contact the author for data requests.

\section{Funding}

There is no funding for this research.

\section{Competing interests}

The author declares that she has no competing interests.

\section{Authors' Contributions}

Shiva Azizpour carried out the study, wrote the manuscript, conceived of the study, designed the study, collected the data, developed a set of interview questions, conducted semi-structured interviews with 13 university professors, manually coded and categorized the transcribed data, and analyzed and reported the transcriptions.

\section{Acknowledgements}

Not applicable.

\section{References}

1. Atai, M. R., \& Dashtestani, R. (2013). Iranian English for academic purposes (EAP) stakeholders' attitudes toward using the Internet in EAP courses for civil engineering students: promises and challenges. Computer Assisted Language Learning, 26(1), 21-38.

2. Atmojo, A. E. P., \& Nugroho, A. (2020). EFL classes must go online! Teaching activities and challenges during COVID-19 pandemic in Indonesia. Register Journal, 13(1), 49-76.

3. Bailey, D. R., \& Lee, A. R. (2020). Learning from experience in the midst of covid-19: benefits, challenges, and strategies in online teaching. Computer-Assisted Language Learning Electronic Journal, 21(2), 178-198.

4. Baru, M., Tenggara, W. N., \& Mataram, M. U. (2020). Promoting Students $\llbracket$ Autonomy through Online Learning Media in EFL Class. International Journal of Higher Education, 9(4), 320-331. 
5. Bozorgian, H. (2018). Teachers' Attitudes towards the Use of MALL Instruction in Iranian EFL Context. The International Journal of Humanities, 25(3), 1-18.

6. Chapelle, C. (2005). "Computer-assisted language learning," in Handbook of Research in Second Language Teaching and Learning, ed. E. Hinkel (Mahwah, NJ: Lawrence Erlbaum Associates), 743755 .

7. Chen, Z., Jiao, J., \& Hu, K. (2021). Formative Assessment as an Online Instruction Intervention: Student Engagement, Outcomes, and Perceptions. International Journal of Distance Education Technologies (IJDET), 19(1), 1-16.

8. Coffey, A., \& Atkinson, P. (1996). Making sense of qualitative data: Complementary research strategies. Sage Publications, Inc.

9. Daniels, L. M., Goegan, L. D., \& Parker, P. C. (2021). The impact of COVID-19 triggered changes to instruction and assessment on university students' self-reported motivation, engagement and perceptions. Social Psychology of Education, 24(1), 299-318.

10. Denzin, N. K., \& Lincoln, Y. S. (2000). The discipline and practice of qualitative research. In N. K. Denzin, \& Y. S. Lincoln (Eds.), The handbook of qualitative research (2nd ed.). (pp. 1-28). London: Sage.

11. Doyumgaç, I., Tanhan, A., \& Kiymaz, M. S. (2021). Understanding the most important facilitators and barriers for online education during COVID-19 through online photovoice methodology. International Journal of Higher Education, 10(1), 166-190.

12. Durrington, V. A., Berryhill, A., \& Swafford, J. (2006). Strategies for enhancing student interactivity in an online environment. College teaching, 54(1), 190-193.

13. Fawaz, M., \& Samaha, A. (2020). COVID-19 quarantine: Post-traumatic stress symptomatology among Lebanese citizens. International Journal of Social Psychiatry, 66(7), 666-674.

14. Feldman, R., \& Zucker, D. (2002). Teaching and Learning Online - Communication, Community, and Assessment. University of Massachusetts.

15. Gao, L. X., \& Zhang, L. J. (2020). Teacher learning in difficult times: Examining foreign language teachers' cognitions about online teaching to tide over COVID-19. Frontiers in Psychology, 11(1), 2396.

16. Garrison, D. R., Anderson, T., \& Archer, W. (2000). Critical inquiry in a text-based environment: Computer conferencing in higher education model. The Internet and Higher Education, 2(2), 87-105.

17. Gasaymeh, A. M. M. (2009). A study of faculty attitudes toward internet-based distance education: A survey of two Jordanian public universities (Doctoral dissertation, Ohio University).

18. Grant-Davie, K. (1992). Coding data: Issues of validity, reliability, and interpretation. In G. Kirsch, \& P. A. Sullivan (Eds.), Methods and methodology in composition research (pp. 270-286). Carbondale: Southern Illinois University.

19. Halim, M. S. A. A., \& Hashim, H. (2019). Integrating web 2.0 technology in ESL classroom: A review on the benefits and barriers. Journal of Counseling and Educational Technology, 2(2), 1-8. 
20. Harwood, N., Austin, L., \& Macaulay, R. (2009). Proofreading in a UK university: Proofreaders' beliefs, practices, and experiences. Journal of Second Language Writing, 18(3), 166-190.

21. Hill, T., \& Westbrook, R. (1997). SWOT analysis: it's time for a product recall. Long Range Planning, $30(1), 46-52$.

22. Holland, A. A. (2019). Effective principles of informal online learning design: A theory-building metasynthesis of qualitative research. Computers \& Education, 128(1), 214-226.

23. Huang, C., Wang, Y., Li, X., Ren, L., Zhao, J., Hu, Y., \& Cao, B. (2020). Clinical features of patients infected with 2019 novel coronavirus in Wuhan, China. The lancet, 395(10223), 497-506.

24. Huang, H. M., \& Liaw, S. S. (2005). Exploring users' attitudes and intentions toward the web as a survey tool. Computers in human behavior, 21(5), 729-743.

25. Jones, R. H. (2013). Research methods in TESOL and digital literacies. Tesol Quarterly, 47(4), 843848.

26. Kaufmann, R., \& Vallade, J. I. (2020). Exploring connections in the online learning environment: student perceptions of rapport, climate, and loneliness. Interactive Learning Environments, 1-15. doi:10.1080/10494820.2020.1749670.

27. Kayzouri, A. H., Mohebiamin, A., Saberi, R., \& Bagheri-Nia, H. (2020). English language professors' experiences in using social media network Telegram in their classes: a critical hermeneutic study in the context of Iran. Qualitative Research Journal, 21(2), 124-134.

28. Keeton, M. T. (2004). Best online instructional practices: Report of phase I of an ongoing study. Journal of Asynchronous Learning Networks, 8(2), 75-100.

29. Khoshsima, H., Saed, A., \& Arbabi, M. A. (2018). Online teachers' attitudes toward using technology in teaching English as a foreign language. Journal of Applied Linguistics and Language Research, 5(2), 134-148.

30. Kia Heirati, J., \& Alashti, L. A. (2015). Attitudes toward using the Internet for language learning: A case of Iranian English teachers and learners. International Journal of Research Studies in Educational Technology, 4(1). doi:10.5861/ijrset.2015.1029.

31. Kim, H. (2002). Teachers as a barrier to technology-integrated language teaching. English Teaching, 57(2), 35-64.

32. Kolesova, D. V., Moskovkin, L. V., \& Popova, T. I. (2021). Urgent Transition to Group Online Foreign Language Instruction: Problems and Solutions. Electronic Journal of e-Learning, 19(1), 21-41.

33. Lee, J. W. (2010). Online support service quality, online learning acceptance, and student satisfaction. Internet and Higher Education, 13, 277-283.

https://doi.org/10.1016/j.iheduc.2010.08.00

34. Liguori, E., \& Winkler, C. (2020). From offline to online: Challenges and opportunities for entrepreneurship education following the COVID-19 pandemic.

35. Liu, W., Zhang, Q. I., Chen, J., Xiang, R., Song, H., Shu, S., \& Liu, Y. (2020). Detection of Covid-19 in children in early January 2020 in Wuhan, China. New England Journal of Medicine, 382(14), 1370- 
1371.

36. Loewen, S., Isbell, D. R., \& Sporn, Z. (2020). The effectiveness of app-based language instruction for developing receptive linguistic knowledge and oral communicative ability. Foreign Language Annals, 53(2), 209-233.

37. Mahmood, S. (2021). Instructional strategies for online teaching in COVID-19 pandemic. Human Behavior and Emerging Technologies, 3(1), 199-203.

38. Means, B., Toyama, Y., Murphy, R., Bakia, M., \& Jones, K. (2009). Evaluation of evidence-based practices in online learning: A meta-analysis and review of online learning studies. Project Report. Centre for Learning Technology.

39. Meishar-Tal, H., \& Levenberg, A. (2021). In times of trouble: Higher education lecturers' emotional reaction to online instruction during COVID-19 outbreak. Education and Information Technologies, 117. https://doi.org/10.1007/s10639-021-10569-1.

40. Miles, M. B., \& Huberman, A. M. (1994). Qualitative data analysis: An expanded sourcebook (2nd ed.). Thousand Oaks: Sage.

41. Moorhouse, B. L. (2020). Adaptations to a face-to-face initial teacher education course 'forced' online due to the COVID-19 pandemic. Journal of Education for Teaching, 46(4), 609-611.

42. Park, Y. J., \& Bonk, C. J. (2007). Is online life a breeze? A case study for promoting synchronous learning in a blended graduate course. MERLOT Journal of Online Learning and Teaching, 3(3), 307323.

43. Pazilah, F. N., Hashim, H., \& Yunus, M. M. (2019). Using technology in ESL classroom; Highlights and challenges. Creative Education, 10(1), 3205-3212.

44. Plaisance, M. (2018). Online Course Delivery. In J. I. Liontas (Ed.), The TESOL Encyclopedia of English Language Teaching(1st ed.). https://doi.org/10.1002/9781118784235.eelt0129

45. Prichard, C. (2013). Using social networking sites as a platform for second language instruction. TESOL Journal, 4(4), 752-758.

46. Reamer, F. G. (2013). Distance and online social work education: Novel ethical challenges. Journal of Teaching in Social Work, 33(4), 369-384.

47. Reinders, H., \& Stockwell, G. (2017). Computer-assisted SLA. The Routledge handbook of instructed second language acquisition, 361-375. doi:10.4324/9781315676968-20.

48. Rosell-Aguilar, F. (2018). Autonomous language learning through a mobile application: a user evaluation of the busuu app. Computer Assisted Language Learning, 31(8), 854-881.

49. Salbego, N. N., \& Tumolo, C. H. S. (2015). Skype Classes: Teachers and students' perceptions on synchronous online classes in relation to face-to-face teaching and learning. International Journal of Language and Applied Linguistics, 1(3), 36-45.

50. Saykılı, A. (2018). Distance education: Definitions, generations, key concepts and future directions. International Journal of Contemporary Educational Research, 5(1), 2-17. 
51. Semerci, A., \& Aydin, M. K. (2018). Examining High School Teachers' Attitudes towards ICT Use in Education. International Journal of Progressive Education, 14(2), 93-105.

52. Silverman, D. (2000). Analyzing talk and text. In N. K. Denzin, \& Y. S. Lincoln (Eds.), The handbook of qualitative research (2nd ed.). (pp. 821-835). London: Sage.

53. Slade, S., \& Prinsloo, P. (2013). Learning analytics: Ethical issues and dilemmas. American Behavioral Scientist, 57(10), 1510-1529.

54. Tanhan, A. (2020). COVID-19 sürecinde online seslifoto (OSF) yöntemiyle biyopsikososyal manevi ve ekonomik meseleleri ve genel iyi oluş düzeyini ele almak: OSF'nin Türkçeye uyarlanması. [Utilizing online photovoice (OPV) methodology to address biopsychosocial spiritual economic issues and wellbeing during COVID-19: Adapting OPV to Turkish.] Turkish Studies, 15(4), 1029-1086. https://doi.org/10.7827/TurkishStudies.44451

55. Toprak, E., Ozkanal, B., Aydin, S., \& Kaya, S. (2010). Ethics in E-Learning. Turkish Online Journal of Educational Technology-TOJET, 9(2), 78-86.

56. Underdown, K., \& Martin, J. (2016). Engaging the online student: Instructor-created video Content for the online classroom. Journal of Instructional Research, 5(1), 8-12.

57. Varble, D. (2014). Reducing cheating opportunities in online test. Atlantic Marketing Journal, 3(3), 131-149.

58. Viner, R. M., Russell, S. J., Croker, H., Packer, J., Ward, J., Stansfield, C., \& Booy, R. (2020). School closure and management practices during coronavirus outbreaks including COVID-19: a rapid systematic review. The Lancet Child \& Adolescent Health, 4(5), 397-404.

59. Xia, J., Fielder, J., \& Siragusa, L. (2013). Achieving better peer interaction in online discussion forums: A reflective practitioner case study. Issues in Educational Research, 23(1), 97-104.

60. Zankova, A.A. (2019). Learning Russian as a foreign language in online environment: Opportunities and peculiarity. The World of Science, Culture and Education, 2(75), 28-29

\section{Supplementary Files}

This is a list of supplementary files associated with this preprint. Click to download.

- Appendix.docx 